\title{
Tribute to Vikram Sarabhai
}

\author{
C. N. R. Rao* \\ Jawaharlal Nehru Centre for Advanced Scientific Research, Bengaluru 560 064, India
}

When I was very young, I remember people doing balloon experiments in the Indian Institute of Science campus, Bangalore. It was young Sarabhai with Homi Bhabha carrying out cosmic ray experiments. Vikram Sarabhai officially had registered for the $\mathrm{Ph} \mathrm{D}$ degree of Cambridge University under the supervision of C. V. Raman, but his immediate guide was Homi Bhabha. Though I could not have known him at that time, I got in touch with him in 1961 when he was the President of the Physics Section of the Indian Science Congress. He had invited me to give a talk on Spectroscopy in Chemistry. After that meeting, we became good friends and met each other on different occasions.

Vikram Sarabhai arranged the meeting of the Indian Academy of Sciences to celebrate the 80th birthday of Prof. Raman in 1968 in Ahmadabad. It was a fantastic occasion where everybody worth the name in science was present. Vikram was a great organizer. On that occasion, I had been invited to talk on some of my research work. About a year later in 1970, we had the last meeting of the Indian Academy of Sciences presided over by Prof. Raman in Bangalore. Prof. Raman had asked me to give a lecture in that meeting. A few weeks after that occasion, Raman passed away. Vikram Sarabhai held Raman in great respect and I equally respected and loved Raman. This was one of the binding forces probably between us.

Vikram Sarabhai became the Chairman of the Atomic Energy Commission after the sad demise of Homi Bhabha in 1966. He was also running the space programme. As chairman of the Atomic Energy Commission, he asked me to be the chairman of the chemistry and metallurgy committee of AEC and some other activities. He had tre-

*e-mail: cnrrao@jncasr.ac.in mendous trust in people. He showed much confidence in my abilities, as he did in many others who worked with him in the space organization and elsewhere.

He visited IIT Kanpur in 1971 when I was the Dean of Research there. He wanted to have a link between IIT Kanpur and BARC to carry out joint educational and research progammes in a mutually beneficial fashion. He asked me to come to Bombay along with the Director to discuss details. When we went to Bombay, we stayed in the Guest Rooms of the BARC. To my great sadness, the next morning, we found that Vikram Sarabhai had just passed away in Trivandrum. I went to the airport to be there when his body was brought to Bombay on a plane from Trivandrum. The date was 31 December 1971 when Vikram was hardly 52 years old.

Vikram Sarabhai used to work very hard. Whatever he took on, got his complete attention and that was so with respect to the space programme as well. He used to go back and forth between Bombay and Trivandrum, and day or night did not matter to him. I still remember Prof. Raman advising him to be careful, not to travel too much, and take care of his health. I used to see him travelling on planes going through innumerable files during the trip.

Vikram Sarabhai was one of the most cultured persons that I have known. He was educated in the true sense. His wife Mrinalini, was a great classical dancer and ran a dance academy. I consider myself lucky to have known a person as sophisticated, as suave, as human and as charming, as Vikram Sarabhai. I have not met anyone like Vikram Sarabhai in my dealings with the scientific community.

There was only one Vikram Sarabhai. This is my tribute to this great soul on his centenary.

doi: $10.18520 / \mathrm{cs} / \mathrm{v} 118 / \mathrm{i} 8 / 1182$ 